\title{
New chemical, bio-optical and physical observations of upper ocean response to the passage of a mesoscale eddy off Bermuda
}

\author{
J. D. McNeil, ${ }^{1}$ H. W. Jannasch, ${ }^{2}$ T. Dickey, ${ }^{1}$ D. McGillicuddy, ${ }^{3}$ M. Brzezinski, ${ }^{4}$ \\ and C. M. Sakamoto ${ }^{2}$
}

\begin{abstract}
A mesoscale eddy advected across the Bermuda Testbed Mooring site over a 30-day period centered on July 14, 1995. Temperature and current measurements along with biogeochemical measurements were used to characterize the biological response of the upper ocean associated with the introduction of nitrate into the euphotic layer due to the doming of isotherms associated with the eddy. Complementary shipboard data showed an anomalous water mass, which extended from a depth of $\sim 50$ to $1000 \mathrm{~m}$, manifesting as a cold surface expression and warm anomaly at depth. Although mesoscale eddies are frequently observed in the Sargasso Sea, the present observations are particularly unique because of the high-temporal-resolution measurements of the new instrumentation deployed on the mooring. Analyzers that measure nitrate plus nitrite were placed at depths of 80 and $200 \mathrm{~m}$ and bio-optical sensors were located at depths of 20, 35, 45, 71, and $86 \mathrm{~m}$. Peak nitrate values of nearly $3.0 \mu M$ at $80 \mathrm{~m}$ and chlorophyll $a$ values of $1.4 \mathrm{mg}$ $\mathrm{m}^{-3}$ at $71 \mathrm{~m}$ were observed, as well as a 25 - to 30 -meter shoaling of the $1 \%$ light level depth. A Doppler shift from the inertial period (22.8 hours) to 25.2 hours was observed in several time series records due to the movement of the eddy across the mooring. Inertial pumping brought cold, nutrient-rich waters farther into the euphotic zone than would occur solely by isothermal lifting. Silicic acid was depleted to undetectable levels owing to the growth of diatoms within the eddy. The chlorophyll $a$ values associated with the eddy appear to be the largest recorded during the 8 years of the ongoing U.S. JGOFS Bermuda Atlantic Time Series Study (BATS) program.
\end{abstract}

\section{Introduction}

Several hypotheses have been forwarded regarding the dominant processes by which nitrate is introduced into the euphotic layer in the open ocean. These have been driven by a desire to account for measurements of new production, which is argued to constrain the amount of biologically fixed material exported to the deep sea [Dugdale and Goering, 1967]. It has been speculated that a significant fraction of new production is fueled by nitrate from the atmosphere via rain [Knap et al., 1991], or by fixing of nitrogen by cyanobacteria [Karl et al., 1992].

Ocean processes on several different temporal and spatial scales are capable of mixing nutrients from deeper waters into the upper layer of the ocean. One process is seasonal convection, which contributes the major portion of nutrients to the upper ocean, but not enough alone to close the carbon budget. Local processes include diapycnal diffusion across the thermocline [Lewis et al., 1986; Garside and Garside, 1995], internal gravity waves within the thermocline [Holloway and Denman, 1989], and erosion of the thermocline induced by wind-stresssurface current interaction [Klein and Costa, 1983; Jenkins and

\footnotetext{
${ }^{1}$ Ocean Physics Laboratory, University of California, Santa Barbara

${ }^{2}$ Monterey Bay Aquarium Research Institute, Moss Landing, California.

${ }^{3}$ Woods Hole Oceanographic Institution, Woods Hole, Massachusetts.

${ }^{4}$ Marine Biotechnology Laboratory, University of California, Santa Barbara.

Copyright 1999 by the American Geophysical Union.

Paper number 1999JC900137.

0148-0227/99/1999JC900137\$09.00
}

Goldman, 1985]. For example, Marra et al. [1990] made shipboard/drifter observations of a wind-induced mixing event in the Sargasso Sea in April 1985, which deepened the mixed layer from $50 \mathrm{~m}$ to $150 \mathrm{~m}$. They reported peak nitrate values of $2.0 \mu M$ followed by peak chlorophyll $a$ values of $1.0 \mathrm{mg} \mathrm{m}^{-3}$.

Features such as eddies advect through regions of the open ocean introducing cooler, nutrient-rich water into the euphotic zone. Related eddy-induced productivity could account for a significant amount of new production in the Sargasso Sea [e.g., Jenkins, 1988; McGillicuddy and Robinson, 1997; McGillicuddy et al., 1998]. McGillicuddy et al. [1998] have presented estimates of annual nitrate fluxes by the various processes described above and suggest that mesoscale eddies, after seasonal convection, are the dominant mechanism.

Many mesoscale eddies (of the order of 100-300 km in diameter) have been observed [Parker, 1971; Lai and Richardson, 1977; Richman et al., 1977; Frankignoul, 1981]; however, few observations relate these eddies to the biological response of the upper ocean. Related work by Granata et al. [1995] focused on observed chlorophyll $a$ enhancement attributed to trapped inertial waves in the vicinity of a front associated with a large mesoscale feature in the Sargasso Sea. Falkowski et al. [1991] observed a cyclonic eddy in the subtropical Pacific and determined that the doming of nitrate-rich isopycnals into the euphotic zone would increase total production by only $20 \%$.

Jenkins [1988] estimated an upward flux of nitrate into the euphotic zone of $0.6 \pm 0.2 \mathrm{~mol} \mathrm{~m}^{-2} \mathrm{yr}^{-1}$ by correlating observed ${ }^{3} \mathrm{He}$ with nitrate and relating this nutrient injection stoichiometrically giving an estimate of new production of 3 mol $\mathrm{C} \mathrm{m}^{-2} \mathrm{yr}^{-1}$. He noted that only a few nutrient pulses due to mesoscale events, when combined with the spring bloom, 
are required annually to support this computed flux, but warned that with monthly sampling cruises the probability of observing such a nitrate pulse directly is only $\sim 1 \%$. Since nutrients are utilized on a very short timescale, one-half day to several days, limited traditional shipboard observations can easily miss the nitrate pulses associated with these eddies and other processes. However, such events may account for a high proportion of annual primary production [e.g., Platt and Harrison, 1985].

A unique data set was obtained at the Bermuda Testbed Mooring site in July 1995, when a mesoscale eddy passed the mooring. The eddy introduced nitrate into the euphotic layer and led to exceptionally large values of chlorophyll $a$ concentrations (and inferred phytoplankton biomass) for this area.

\section{Methods}

The Bermuda Testbed Mooring (BTM) provides a platform from which new oceanographic instrumentation may be tested for their ability to acquire high-resolution serial observations of interdisciplinary ocean properties over a long duration [Dickey et al., 1998a]. The site for the mooring $\left(31^{\circ} 43.7^{\prime} \mathrm{N}\right.$, $64^{\circ} 10.1^{\prime} \mathrm{W}$, in the Sargasso Sea) was chosen because it is within a representative oligotrophic gyre, is in deep waters $(\sim 4550$ $\mathrm{m})$, has an extensive historical data set, and is a short distance $(\sim 80 \mathrm{~km})$ from Bermuda. The U.S. Joint Global Ocean Flux Study (JGOFS) Bermuda Atlantic Time Series Study (BATS) program, which uses the same location, provides a complementary data set for intercomparison [Michaels and Knap, 1996]. Measurements of hydrography, nutrients, and pigments obtained by the BATS program complement the mooring observations. The BATS sampling protocols are outlined by Knap et al. [1991].

Typical BTM deployments are about 4 months in duration. During mooring turnarounds, instruments are examined, refurbished, and redeployed or replaced. The mooring has provided time series measurements of physical, chemical, and bio-optical oceanic properties since June 1994.

A schematic of the mooring and some of the attached instrument packages are shown in Figure 1. Many of the instrument packages deployed in 1994, such as the multivariable moored system (MVMS) and the moored optical radiometer system (MORS), have proven reliable and continue to be deployed [Dickey et al., 1998a].

In situ analyzers that measure nitrate plus nitrite concentrations [Jannasch et al., 1994] were deployed at depths of $80 \mathrm{~m}$ and $200 \mathrm{~m}$. These analyzers collected high-frequency (10-min sampling rate), nitrate plus nitrite measurements and will be referred to as nitrate analyzers in the remainder of the paper. Note that nitrite concentrations are generally much less than nitrate concentrations. Unfortunately, the 200-m nitrate analyzer failed prior to the time period of the present analysis.

The data obtained from the 71-m MVMS and the nitrate analyzer at $80 \mathrm{~m}$ are of primary interest for this study. The instrumentation on the MVMS included a current meter [Weller and Davis, 1980]; a Sea-Bird Electronics Inc. temperature sensor; a beam transmissometer, which measures the beam attenuation coefficient (beam $c$ ) at $660 \mathrm{~nm}$ and roughly assesses suspended particle concentration (Sea Tech Inc.) [Bartz et al., 1978]; a stimulated fluorometer (Sea Tech Inc.) [Bartz et al., 1988], which measures in vivo fluorescence associated with chlorophyll $a$ concentrations; and a scalar irradiance sensor (Biospherical Instruments Inc.) [Booth, 1976], which measures photosynthetically available radiation (PAR). The sampling rate for all instruments on the MVMS was 16 samples/h. A second MVMS was located at $45 \mathrm{~m}$, and additional current meters (S4 with a 30-min sampling interval) were located at depths of 25 and $106 \mathrm{~m}$. Fluorometers were also located at depths of 20 and $86 \mathrm{~m}$, and additional temperature sensors were located at depths of $25,60,80,106,120$, and $150 \mathrm{~m}$

The fluorometers were calibrated to obtain chlorophyll $a$ using Thallassiosira weissflogii species and compared with Turner chlorophyll $a$ values obtained from the BATS data set during the same period [Knap et al., 1993]. Meteorological data included air temperature, surface PAR, and wind speed and direction. The BTM and its instrumentation are described in detail by Dickey et al. [1998a].

\section{Discussion of Observations}

The period of the third BTM deployment (April 5 to August 23 , 1995) was characterized by three major processes: (1) springtime stratification and warming of the upper layer, (2) passage of a major subsurface eddy, and (3) upper ocean forcing by Hurricane Felix. The response due to the passage of Hurricane Felix is discussed by Dickey et al. [1998b].

Time series of temperature from 45 to $150 \mathrm{~m}$, along with nitrate at $80 \mathrm{~m}$, chlorophyll $a$ at $71 \mathrm{~m}$, and beam attenuation coefficient $(660 \mathrm{~nm})$ at $71 \mathrm{~m}$ are shown in Plate 1 . The two high-nitrate events during April 1995 are likely remnants of the spring bloom. The chlorophyll $a$ time series shows little biological response, possibly because of a shortened residence time in the euphotic zone caused by deep mixing. Once the stratified layer reforms, a biological response to the nitrate in the euphotic layer can be observed in the chlorophyll $a$. Other short-lived episodic nitrate events are evident in May and June; the dips in temperature at $45,60,71$, and $80 \mathrm{~m}$ hint that these pulses may be attributed to mesoscale features.

A major, sustained nitrate increase in the euphotic layer is observed during July 1995 along with a substantial decrease in temperature of the upper ocean layer (Plate 1) except at the sea surface. There is still stratification in the upper $80 \mathrm{~m}$, so deep convective mixing is not occurring. The combination of stratification, high solar insolation (not shown), and high nitrate concentration results in a substantial increase in chlorophyll $a$ and beam $c$ and, by inference, phytoplankton biomass (Plate 1).

Stickplots of rotational currents at depths of $25,45,71$, and $106 \mathrm{~m}$ are shown in Figures 2a (24-hour average) and 2b (2-hour average), and a temperature contour plot with $1 \%$ PAR depth is shown in Plate 2. Currents were separated into rotational and translational components assuming circular symmetry of the eddy for a 30-day period centered on July 14 . Note that there is a 4-day gap in the data at $106 \mathrm{~m}$ due to temporary failure of the S4 current meter (July 19-23). A subsurface isothermal feature passed the BTM mooring over the course of 30 days centered on July 14. Maximum rotational current speeds were approximately $50 \mathrm{~cm} \mathrm{~s}^{-1}$. Inertial currents are evident at 25 and $45 \mathrm{~m}$ but are less pronounced at 71 and $106 \mathrm{~m}$ (Figure 2b). This is an important feature that is discussed below.

The doming of isotherms as observed in the contour plot shown in Plate 2, and the duration of the feature are indicative of a mode water mesoscale eddy [e.g., Frankignoul, 1981]. The eddy advected in a west-northwest direction through the moor- 


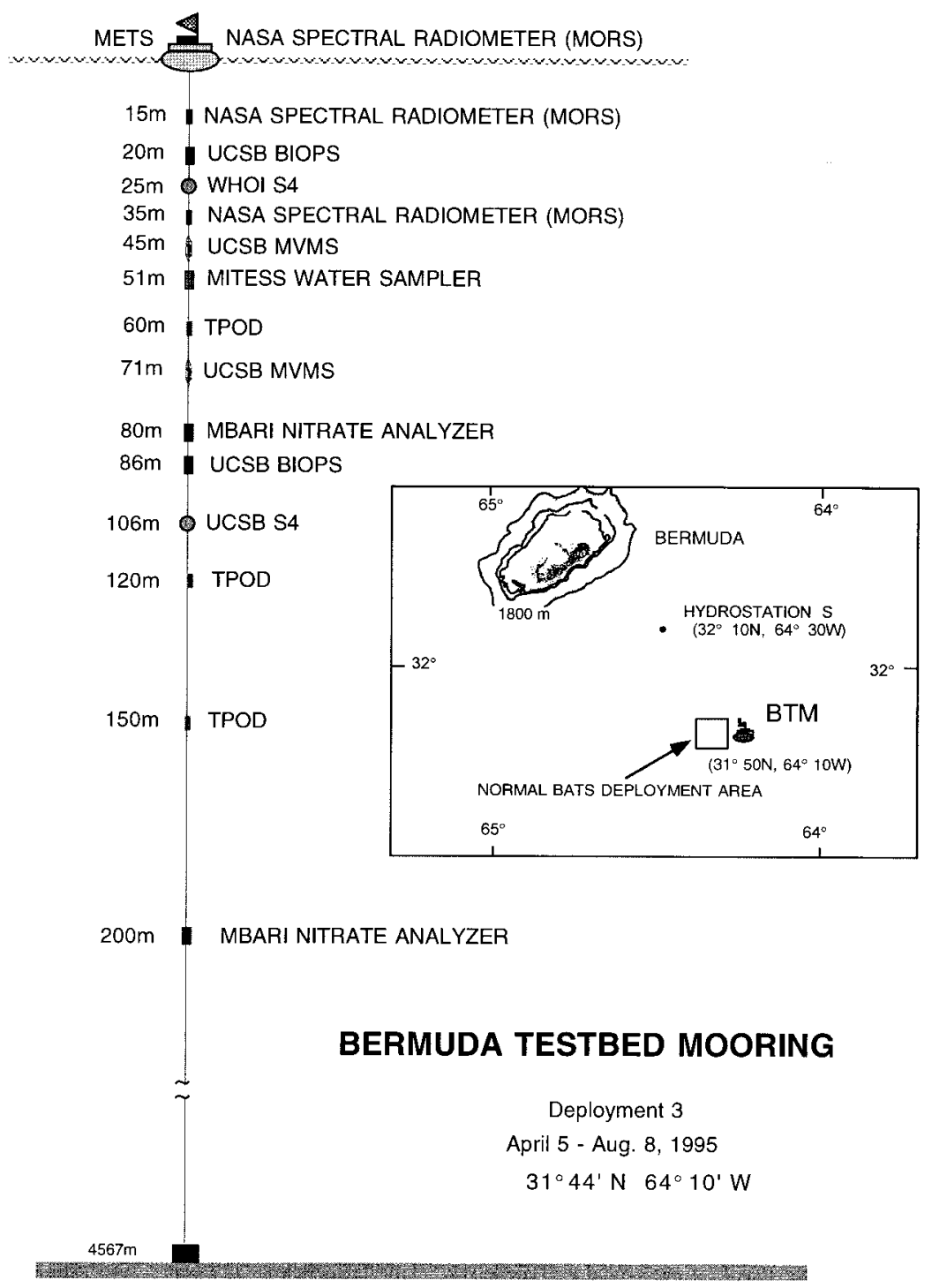

Figure 1. Schematic of Bermuda Testbed Mooring showing depths of instrument packages. The map inset shows the mooring location in relation to the island of Bermuda and the U.S. JGOFS BATS site. Abbreviations not defined in text are MBARI, Monterey Bay Aquarium Research Institute; METS, meteorological sensors; MITESS, Moored In Situ Trace Element Serial Sampler; TPOD, temperature pod; UCSB, University of California, Santa Barbara; and WHOI, Woods Hole Oceanographic Institution.

ing site at about $4.0 \mathrm{~cm} \mathrm{~s}^{-1}$, and given a duration of 1 month for passage, the eddy diameter is approximately $100 \mathrm{~km}$. The velocity vectors shown in the stick plot time series of Figure $2 \mathrm{a}$ rotate in a clockwise sense as observed at the mooring. BATS hydrographic data show a lens of anomalous water (different $T-S$ signature than surrounding Sargasso Sea water) extending from a depth of $\sim 1000 \mathrm{~m}$ to $50 \mathrm{~m}$ that has a relatively cold near-surface expression $(<200 \mathrm{~m})$ and a warm anomaly at depth below the main thermocline (200 to $1000 \mathrm{~m}$ ) (Figures $4 \mathrm{a}$ and $4 \mathrm{c}$ below). The total currents at $106 \mathrm{~m}$ are nearly zero on July 14, indicating that the center of the eddy passed very near the mooring. The isotherm doming is most intense on July 14 (Plate 2), the same period of time when the currents pass through the near zero point, supporting this assertion.

Prior to the passage of the eddy, $18^{\circ}-18.5^{\circ} \mathrm{C}$ water is observed only by the 150 -m-depth moored temperature sensor (Plate 2). As the eddy translates past the mooring, water in the temperature range of $18^{\circ}-18.5^{\circ} \mathrm{C}$ is observed at depths of $71 \mathrm{~m}$ with isopycnal displacements carrying $18^{\circ}-18.5^{\circ} \mathrm{C}$ water up to depths as shallow as $40 \mathrm{~m}$. This suggests that there is a large nitrate flux into the euphotic zone of roughly $64 \mathrm{mmol} \mathrm{m}^{-2}$ per eddy event as based upon tables of nitrate flux versus isotherm displacement from McGillicuddy and Robinson [1997] and estimations from the temperature and nitrate water data from a depth of $150 \mathrm{~m}$. Note that events are based upon a 30-day sampling interval. The chlorophyll $a$ time series indicates a large increase in phytoplankton biomass in response to the nitrate flux. A chlorophyll $a$-based model of light penetration [Ohlmann et al., 1996] shows that the $1 \%$ light level just prior to the time when the eddy reaches the mooring is between 85 and $90-\mathrm{m}$ depth and then shoals to between 60 and $65 \mathrm{~m}$ during the eddy passage (Plate 2).

Time series of temperature, nitrate, chlorophyll $a$, and beam $c$ are shown in Plate 3 for the period June 29 to July 29, 


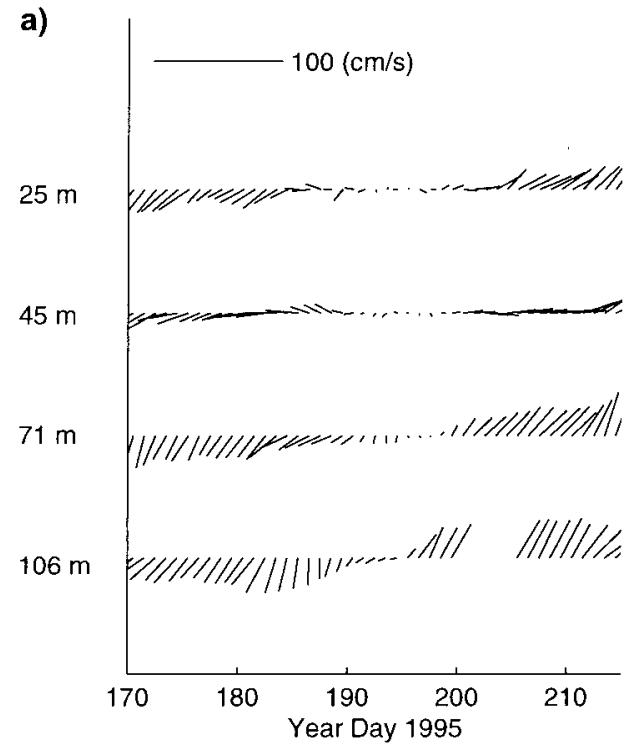

June $19 \quad$ July $4 \quad$ July $19 \quad$ Aug. 3 b)

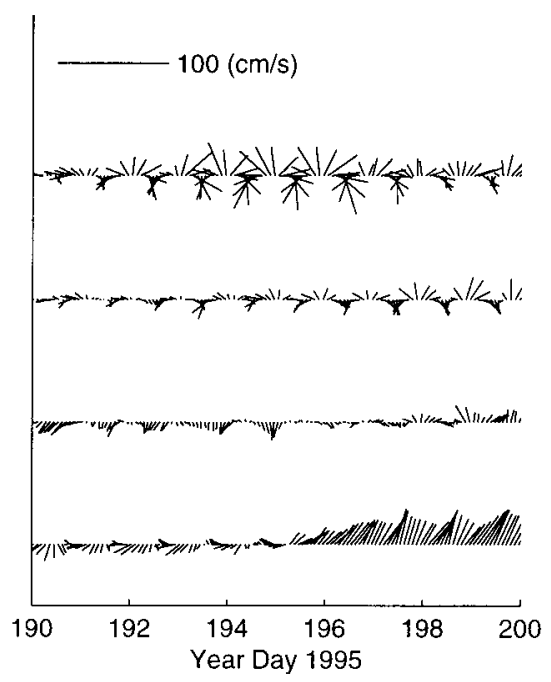

July 9

July 19

Figure 2. Stick plots of vector rotational currents at depths of 25, 45, 71, and $106 \mathrm{~m}$ : (a) 24-hour-averaged currents showing turning of the eddy feature and (b) 2-hour-averaged currents showing inertial oscillations.

focusing on the eddy feature. Prior to the arrival of the eddy, the mooring temperature record shows near surface warming, building of the summer stratification, and shoaling of the mixed layer to $<25 \mathrm{~m}$ (not shown). The advection of the eddy past the mooring site dramatically interrupted this trend in the upper layer with temperatures decreasing by as much as $1.5^{\circ} \mathrm{C}$ at a depth of $45 \mathrm{~m}$ and a subsequent increase in nitrate to peak values of $2.5 \mu \mathrm{mol} \mathrm{L}^{-1}$ at $80 \mathrm{~m}$. Approximately 2 days after the initial increase in nitrate, there was a rapid increase in peak chlorophyll $a$ values to $\sim 1.4 \mathrm{mg} \mathrm{m}^{-3}$ and a concurrent large increase in beam $c\left(<0.6 \mathrm{~m}^{-1}\right)$. Note that the nitrate pulse at $80 \mathrm{~m}$ ends on July 17, yet large values of chlorophyll $a$ and beam $c$ at $71 \mathrm{~m}$ persist for another 8 days. The reason for this is not known. However, since the uptake of nitrate typically requires a few days at most, the elevated chlorophyll $a$ biomass at $71 \mathrm{~m}$ may have been sustained through nutrient recycling, or it may be the result of advection of biomass. Another possibility is that the nitrate analyzer failed during this time period. However, there is a rising trend in the 71-m and 80-m temperature records during the time when the nitrate decreases, whereas the $120-\mathrm{m}$ temperature remains constant. This suggests a sharp nutricline and that the nutrient-rich, cold water resided just below the nitrate sensor, placing the dome of the eddy below $80 \mathrm{~m}$ at this time.

The first significant nitrate pulse appeared on July 2, and chlorophyll $a$ and beam $c$ began increasing on July 4 (Plate 2). The nitrate concentration reached peak values of nearly 2 $\mu \mathrm{mol} \mathrm{L}{ }^{-1}$ on the evening of July 5 , and chlorophyll $a$ and beam attenuation reached their first peaks on approximately July 7 . Thus there appears to be nearly a 2-day lag between the first large nitrate pulse as seen at $80 \mathrm{~m}$ and the response of the phytoplankton as determined from the chlorophyll $a$ at $71 \mathrm{~m}$. This 2-day lag is consistent with the extent of isopycnal doming in the eddy and its translational speed. Assuming a linear gradient of the isopycnal surface, an eddy translational speed of $3.5 \mathrm{~km} \mathrm{~d}^{-1}$, and a doming of the $18^{\circ} \mathrm{C}$ water from 150 to $50 \mathrm{~m}$, then the time for the nitrate to reach $70 \mathrm{~m}$ once it is detected at $80 \mathrm{~m}$ can be estimated. Given an eddy radius of 50 $\mathrm{km}$, the slope of the eddy front is then $100 \mathrm{~m}$ divided by $50 \mathrm{~km}$, or $2 \mathrm{~m} \mathrm{~km}^{-1}$. The time for the nitrate to reach $70 \mathrm{~m}$ once it had reached $80 \mathrm{~m}$ would then be 1.4 days. The biological response to the nutrient injection would be of the order of half a day.

The strong inverse correlation between nitrate concentration and temperature can be seen in the time series of temperature at $71 \mathrm{~m}$ and nitrate at $80 \mathrm{~m}$ (Figure 3 ). In contrast, the changes in beam $c$ are at times nearly in phase with the temperature changes, indicating that particulate matter from the phytoplankton bloom is within the warmer waters (upper layer). The observed period of the nitrate pulses, temperature displacements, and beam $c$ variations is about 25.2 hours.

The inertial period in the vicinity of the mooring is 22.8 hours, so a period of 25.2 hours does not match the inertial period or the diurnal period. White [1972] reported that for moored temperature spectra, the inertial spectral peaks could be slightly higher or lower than the local inertial frequency. He attributed such observations to a Doppler shifting of the frequency of the inertial wave by the zonal mean flow past the moored sensors. The observed frequency would then be given by

$$
f_{\mathrm{o}}=f \pm U_{0} / \lambda
$$

where $f_{\mathrm{o}}$ is the observed frequency, $f$ is the local inertial frequency, $U_{0}$ is the mean zonal flow and $\lambda$ is the zonal wavelength. The plus sign is taken for mean flow in the direction of the inertial wave and the minus sign is taken for mean flow in the opposite direction of the inertial wave. Taking $U_{0}$ to be approximately $-5 \mathrm{~km} \mathrm{~d}^{-1}$ for the eddy and the wavelength to be the inverse of the eddy radius $(50 \mathrm{~km})$, the observed nearinertial frequency would be 0.0397 hour $^{-1}$, giving an observed inertial period of 25.2 hours. Therefore it is possible that the shifting of temperature may be attributed to the Doppler shift due to the mean flow of the eddy past the mooring. The observed inertial pumping of $18^{\circ} \mathrm{C}$ waters from $80 \mathrm{~m}$ to $45 \mathrm{~m}$ could represent an important mechanism for lifting nitrate 

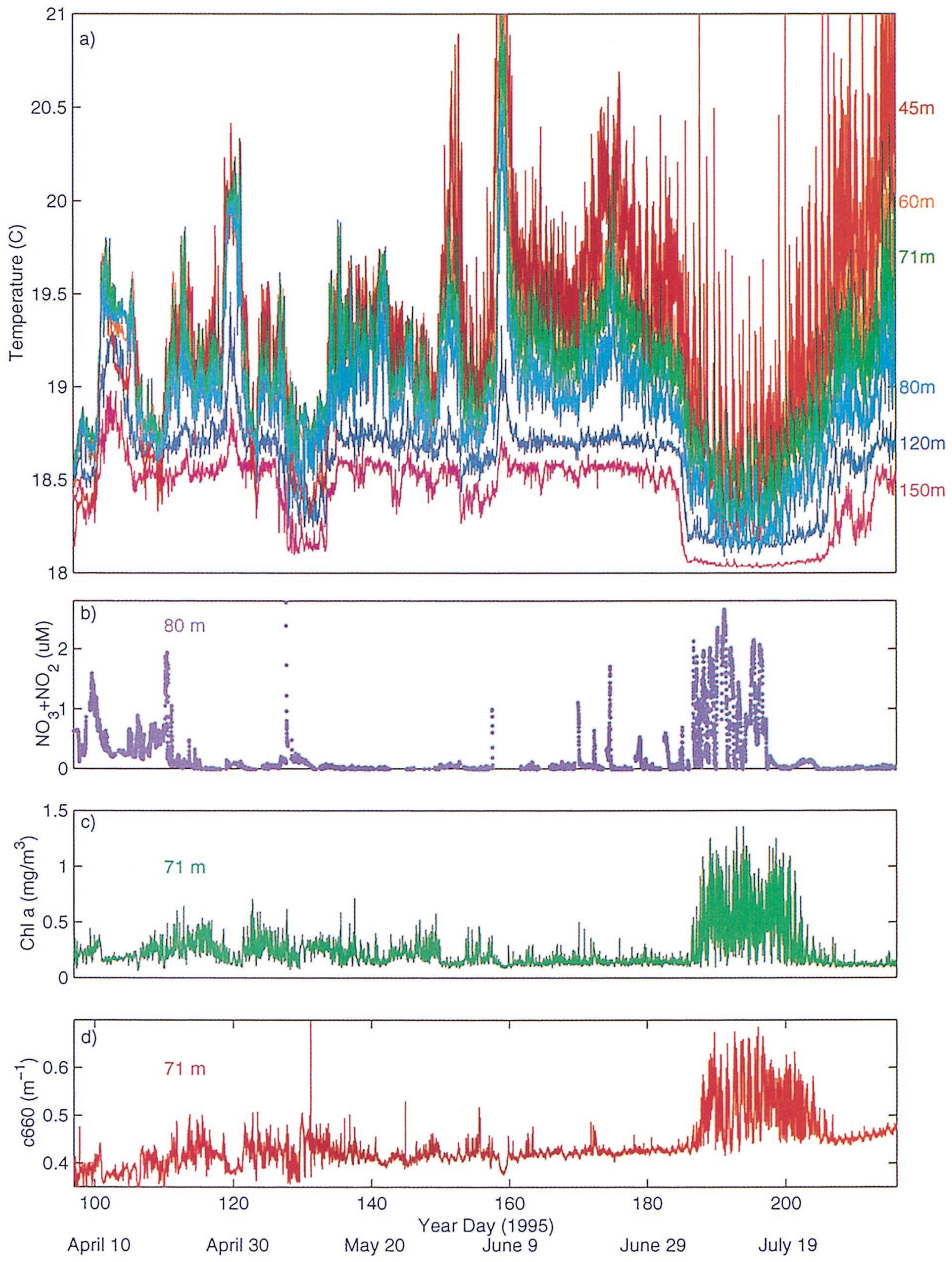

Plate 1. Time series of the third deployment of the Bermuda Testbed Mooring showing (a) temperature at depths of 45-150 m, (b) $\mathrm{NO}_{3}^{-}+\mathrm{NO}_{2}$ at $80 \mathrm{~m}$, (c) chlorophyll $a$ at $71 \mathrm{~m}$, and (d) beam $c$ at $71 \mathrm{~m}$. 

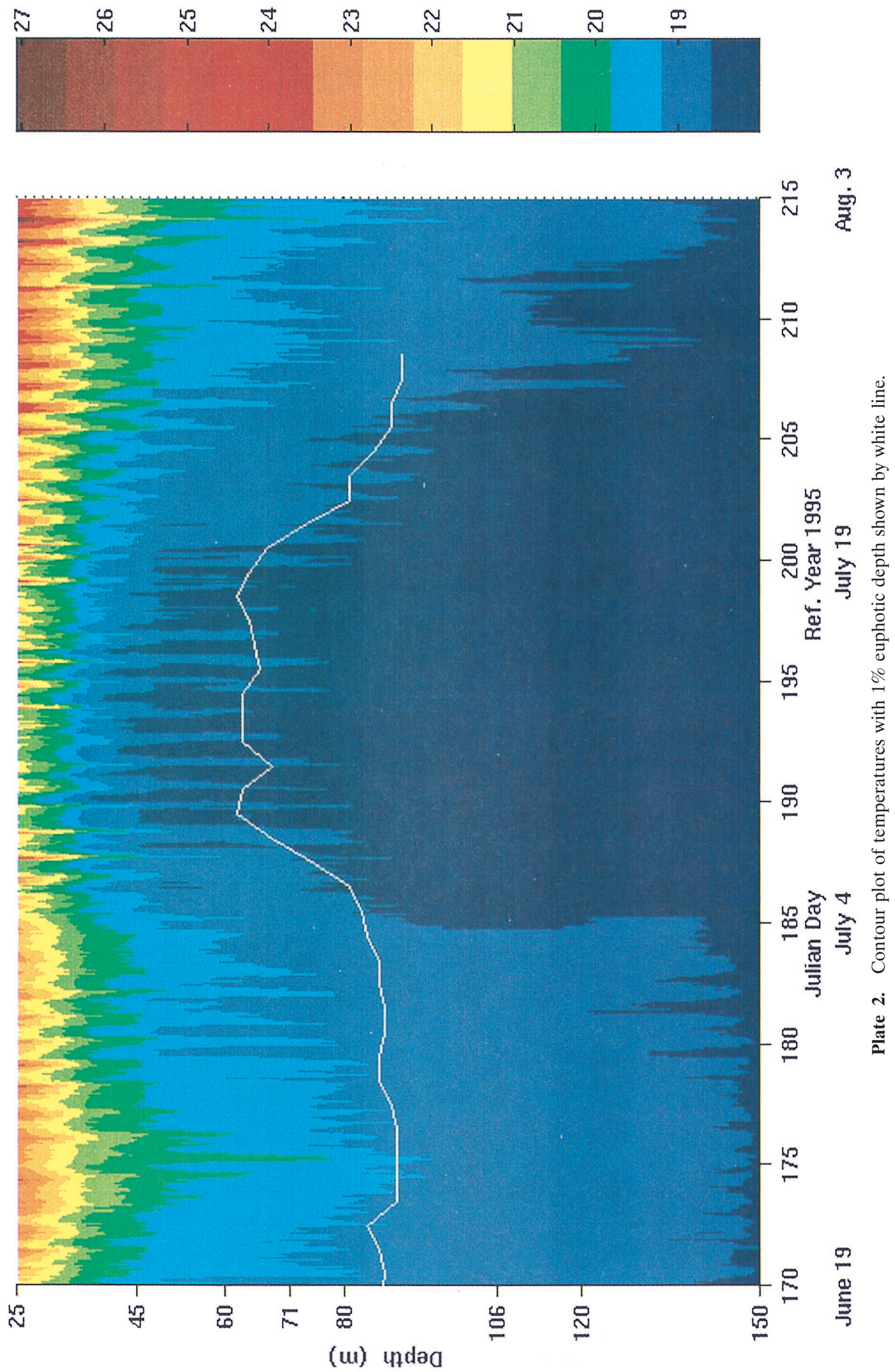

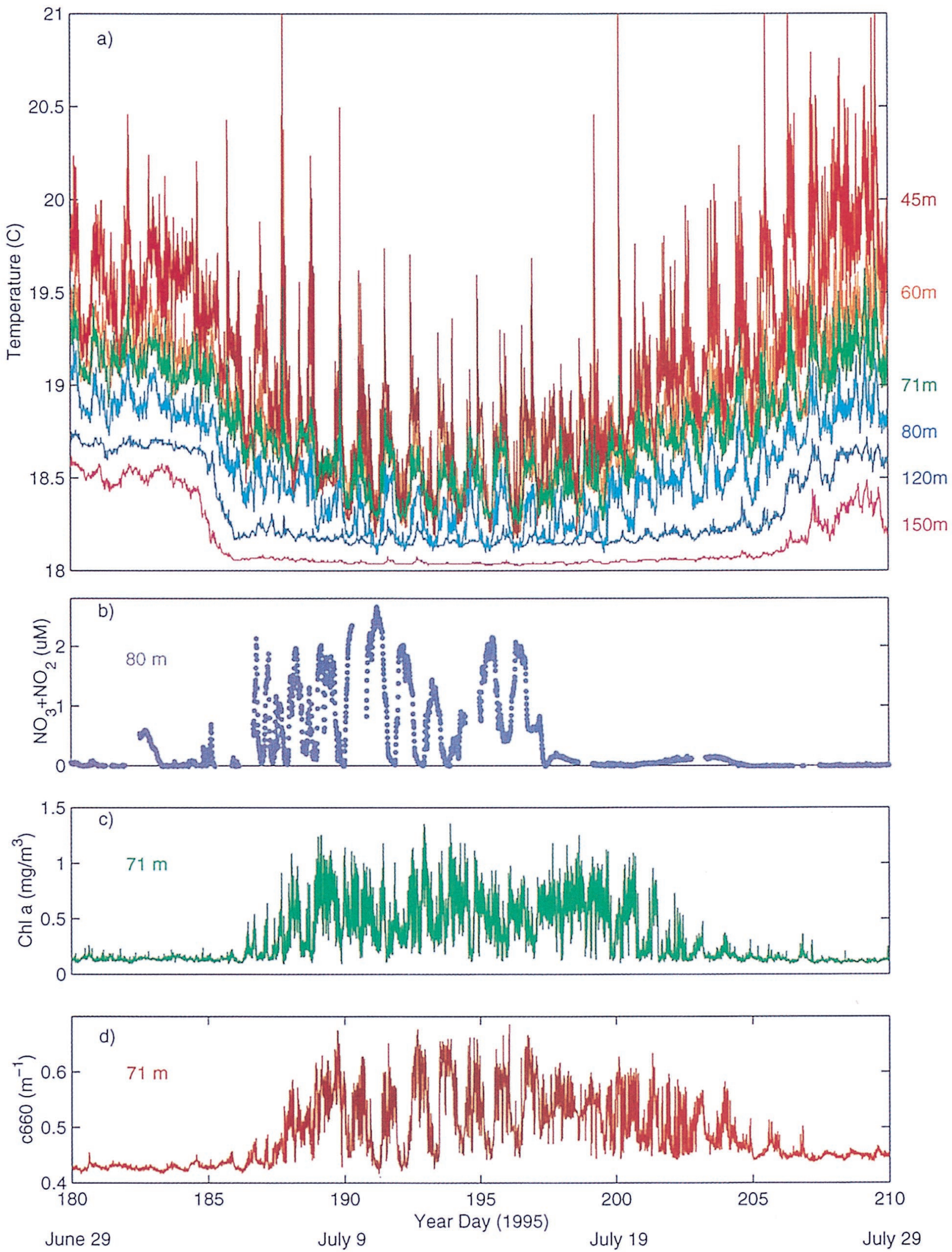

Plate 3. Expanded time series of the same properties as plotted in Plate 1 from June 29 to July 29, 1995. 

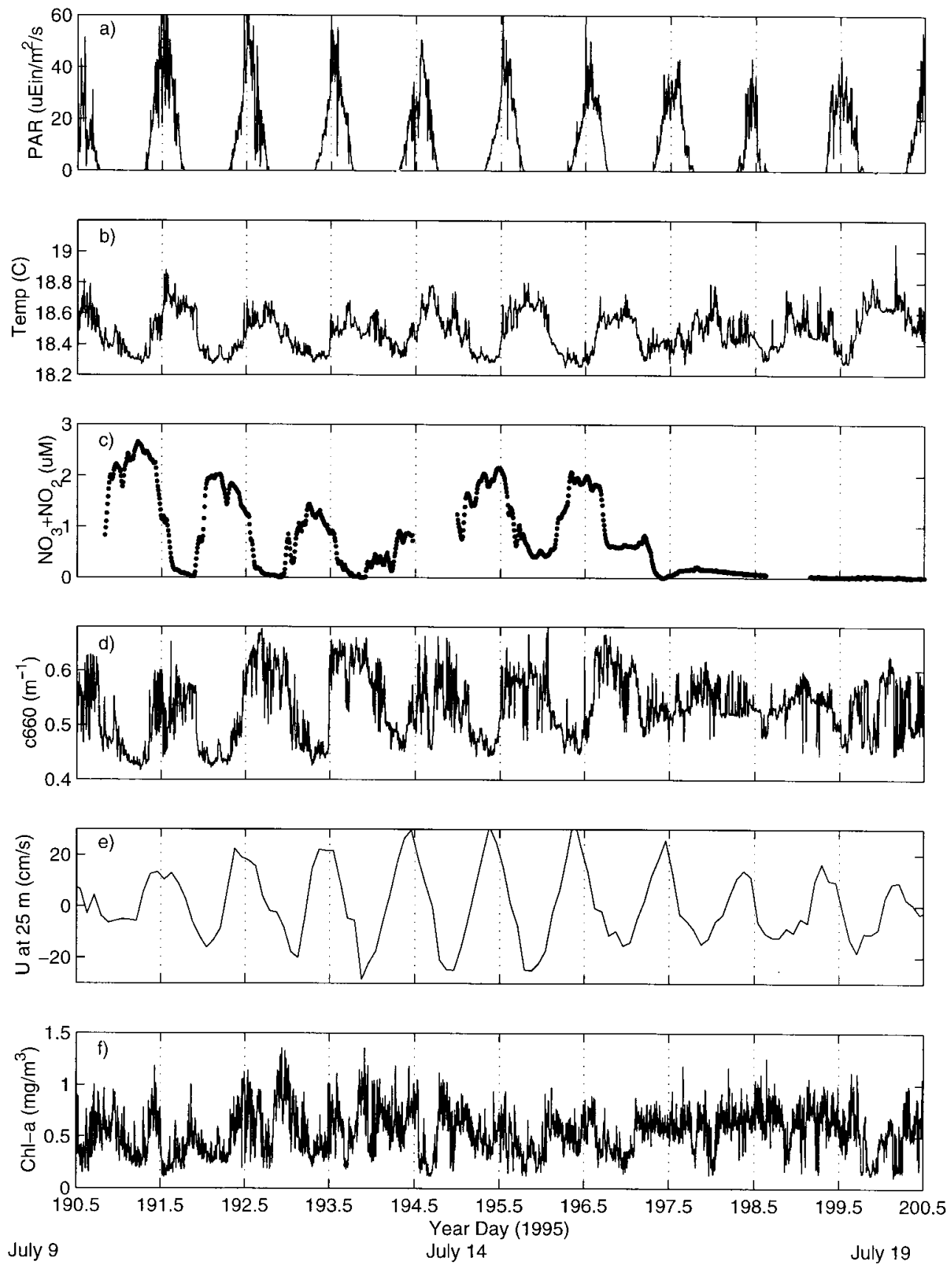

Figure 3. Time series of (a) PAR at $71 \mathrm{~m}$, (b) temperature at $71 \mathrm{~m}$, (c) $\mathrm{NO}_{3}^{-}+\mathrm{NO}_{2}$ at $80 \mathrm{~m}$, (d) beam $c$ at $71 \mathrm{~m}$, (e) zonal current at $25 \mathrm{~m}$, and (f) chlorophyll $a$ at $71 \mathrm{~m}$, from July 9 to 19, 1995.

higher up into the euphotic zone (Figure 2) as the doming of the eddy lifts nitrate only to the base of the euphotic zone. The intensification and subsequent decay of the currents over this period is well fit by a sine curve at the inertial period $(22.8$ hours) modulated by a sine curve with an assumed eddy period of 25 days. Thus inertial currents, although intensified by the eddy, remain at a period of 22.8 hours. Inertial ringing is most intense over the 10-day period centered about the peak of the temperature dome (Plate 2). Similar intensification has been described by Weller [1982] and Kunze [1985].

Three hydrographic casts taken from complementary BATS data are shown in Figure 4: the first cast was taken prior to the eddy (12 June), the second during the passage of the eddy (11
July), and the third after the eddy had passed the mooring (August 18). The deep profiles of temperature and salinity (Figures $4 \mathrm{a}$ and $4 \mathrm{~b}$ ) show that an anomalous water mass associated with the eddy passed the mooring site; the water mass has the same $T-S$ properties before and after the feature. Above the main thermocline (Figures $4 \mathrm{c}$ and $4 \mathrm{~d}$ ), the signatures of the eddy are colder and fresher waters, while below the main thermocline the water is relatively warmer and more saline than the surrounding water. At depths greater than $1000 \mathrm{~m}$ the water masses for all three casts are nearly the same. The surface waters of the eddy are slightly warmer and much less saline. These measurements confirm that an anomalous lens of water was riding upon the main thermocline during July 

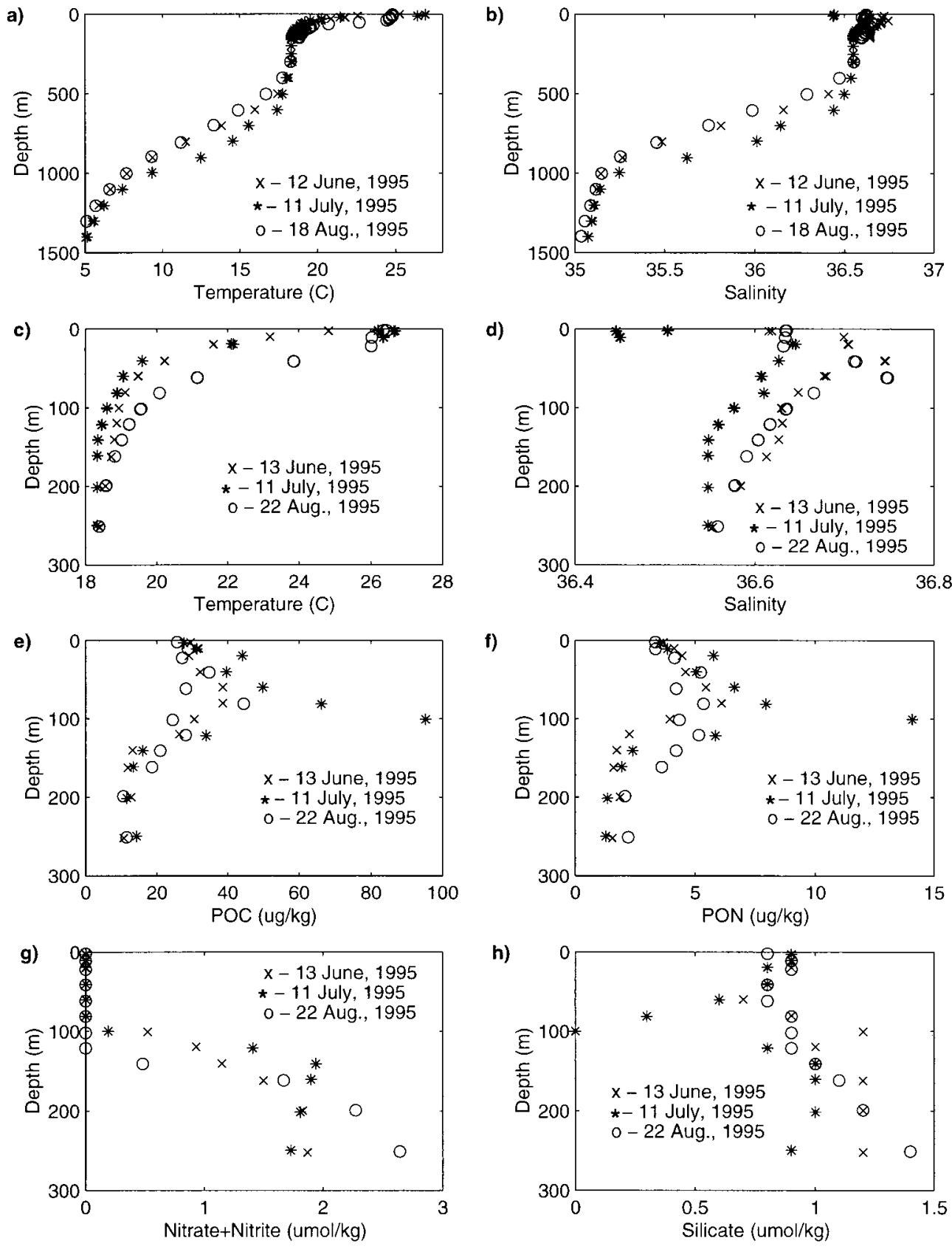

Figure 4. Shipboard measurements from the BATS site: (a) temperature to $1500-\mathrm{m}$ depth, (b) salinity to 1500-m depth, (c) temperature to 300-m depth, (d) salinity to 300-m depth, (e) particulate organic carbon (POC), (f) particulate organic nitrogen (PON), (g) nitrate and nitrite, and (h) silicate.

1995 at the mooring site. This associated hydrographic structure is suggestive of a second baroclinic mode. Frankignoul [1981] analyzed 24 years of hydrographic data obtained at the Hydrostation S (Panulirus data) site $25 \mathrm{~km}$ southeast of Bermuda. His results indicated that the first two baroclinic normal modes explained $60 \%$ and $23 \%$ of the variance, respectively. Thus the structure of the eddy described here is apparently not uncommon. It is also interesting to note that Simpson et al. [1983] gave a detailed account of a mesoscale eddy observed in the California Current system with a signature very similar to that of the present eddy.

Particulate organic carbon (POC) and particulate organic nitrogen (PON) increased twofold to threefold at the base of the euphotic zone during the passage of the eddy (Figures $4 \mathrm{e}$ and 4f), yet nitrate plus nitrite concentrations are not elevated in the upper $100 \mathrm{~m}$ (Figure $4 \mathrm{~g}$ ). This demonstrates the importance of high-resolution serial sampling, as the bottle samples obtained from shipboard casts do not show the nitrate event observed in the mooring time series record.

Further evidence for the stimulation of new production by the eddy is provided by discrete bottle samples of highperformance liquid chromatography (HPLC) and Turner pigments shown in Figure 5. Turner chlorophyll $a$, Turner phaeopigments, and HPLC-determined chlorophyll $a$ (Figures 5a to 5 c) all increase by a factor of $2-3$ at $\sim 100 \mathrm{~m}$ within the eddy. The BATS fluorometer profiles also show the largest values 

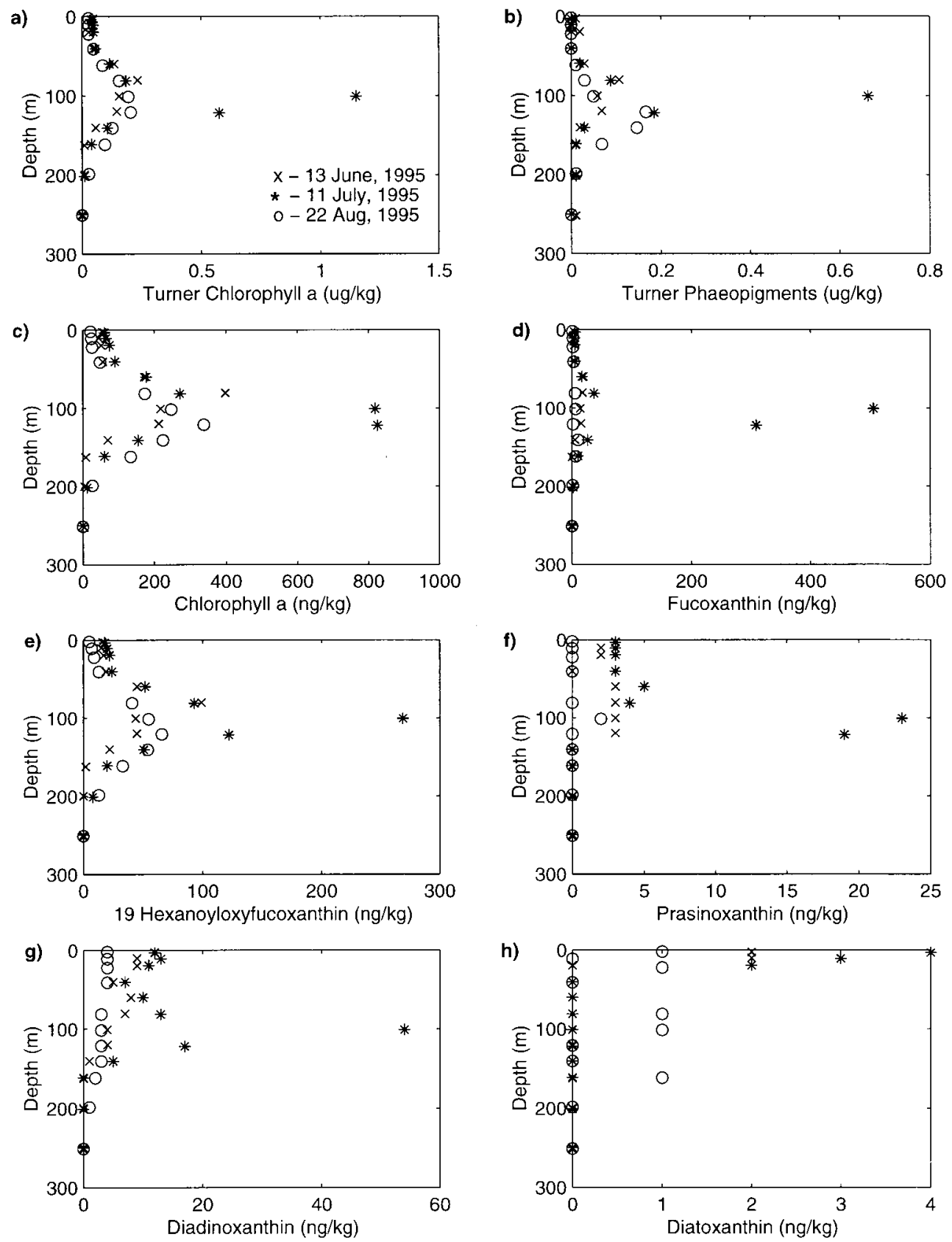

Figure 5. HPLC pigments and fluorometric pigments from BATS discrete bottle samples: (a) Turner chlorophyll $a$, (b) Turner phaeopigments, (c) chlorophyll $a$, (d) fucoxanthin, (e) 19-hexanoyloxyfucoxanthin, (f) prasinoxanthin, (g) diadinoxanthin, and (h) diatoxanthin.

observed during the entire BATS program's time series. These results are consistent with the chlorophyll $a$ results obtained from the moored fluorometers that show increases of approximately a factor of 10 at 71 and $86 \mathrm{~m}$. The chlorophyll $a$ concentrations of $>1.0 \mathrm{mg} \mathrm{Chl} a \mathrm{~m}^{-3}$ at $71 \mathrm{~m}$ obtained with the fluorometer are comparable to values observed during the spring bloom (BATS database).

Simple scale analysis was performed to estimate vertical versus horizontal advection of chlorophyll $a$ concentrations using the eddy's translational speed and best estimates of vertical and horizontal gradients of key physical and biological variables. This analysis indicated that vertical advection was the dominant process. Given this information, the total chlo- rophyll $a$ derivative and vertical advection of chlorophyll $a$ were calculated from the time series, and the local derivative was computed by difference. The results showed that on the average, local production of chlorophyll $a$ was substantially larger than vertical advection of chlorophyll $a$. Thus the large chlorophyll $a$ values obtained at the mooring during the eddy are likely attributable to new production. This suggests that only a small number of mesoscale eddies per year may account for the deficiency in new production as determined solely from the spring bloom [McGillicuddy and Robinson, 1997].

HPLC pigment analyses of BATS discrete bottle samples [Knap et al., 1991] (Figure 5) indicate that diatoms dominated phytoplankton biomass within the eddy. There was a 3 order of 
magnitude increase in the concentration of fucoxanthin (Figure 5d), which is indicative of diatoms [Bidigare et al., 1990], within the eddy. Diatoxanthin (Figure 5g), which can indicate the presence of diatoms and all classes of heterokontophyta, showed a large increase at the surface, growing from near zero between June 13 and July 11. Other phytoplankton groups were also more abundant within the eddy: 19-hexanoyloxyfucoxanthin (prymnesiophytes; Figure 5e) increased by a factor of 3, prasinoxanthin (prasinophytes; Figure 5f) increased by a factor of 4-5, and diadinoxanthin (all classes of heterokontophyta; Figure 5h) increased by a factor of 6-12.

Diatoms have an obligate need for silicate to produce their siliceous frustules [Lewin, 1962]. Their growth within the eddy depleted silicic acid concentrations to undetectable levels at the base of the euphotic layer (compare Figures $4 \mathrm{~h}$ and $5 \mathrm{~d}$ ). Such severe depletion of silicic acid in this region is unprecedented. A 6-year time series of silicic acid concentrations in the upper $150 \mathrm{~m}$ at the BATS site (October 1988 to December 1994) reveals no undetectable silicic acid concentrations in the upper $150 \mathrm{~m}$ [Nelson and Brzezinski, 1997] with all but 2 of 957 measurements being $>0.5 \mathrm{~m} M$ (data from BATS archive). Enhanced diatom silica production rates at the base of the euphotic zone have been observed before in the Sargasso Sea [Brzezinski and Kosman, 1996; Nelson and Brzezinski, 1997], but local depletion of silicic acid has never been observed with these events. Past observations suggest that diatom growth at the base of the euphotic zone accounts for up to $24 \%$ of the annual new production for the Sargasso Sea. The very strong response of diatoms to nutrient pumping in the eddy suggests that the contribution of diatoms to new production in mesoscale features is considerably higher.

Although there was only one nitrate sensor functioning on the mooring during the eddy passage, four fluorometers collected data at depths of 20,45, 71, and $90 \mathrm{~m}$. The integrated chlorophyll $a$ was roughly estimated from these four instruments. Profiles of chlorophyll $a$ were approximated from the four depths at which fluorometers were located and then averaged over 1 day after subtracting out the mean chlorophyll $a$ obtained from the entire time series. Daily averaged chlorophyll $a$ profiles were integrated over the euphotic depth and then averaged over time from July 4 to July 24 (the time over which the chlorophyll signal is clearly above the long-term mean value). This resulted in an average value of $7.3 \mathrm{mg} \mathrm{m}^{-2}$ of chlorophyll $a$ within the eddy per day. Using the approximate relation of $1 \mu \mathrm{M} \mathrm{NO}_{3}^{-}=1 \mathrm{mg} \mathrm{m}^{-3}$ chlorophyll $a$ [Marra et al., 1990], the amount of nitrate consumed per day to produce that amount of chlorophyll $a$ is estimated to be $7.3 \mathrm{mmol}$ $\mathrm{NO}_{3}^{-} \mathrm{m}^{-2}$. That is equivalent to a nitrate-based production of the order of $53 \mathrm{mmol} \mathrm{C} \mathrm{m} \mathrm{d}^{-2} \mathrm{~d}^{-1}$, or $630 \mathrm{mg} \mathrm{C} \mathrm{m}^{-2} \mathrm{~d}^{-1}$ within the eddy (using the stoichiometric relation of $1 \mathrm{NO}_{3}^{-}: 7.2 \mathrm{C}$ ). This estimate is consistent with that obtained above from McGillicuddy and Robinson [1997] and can be compared with typical open-ocean values of $300-360 \mathrm{mg} \mathrm{C} \mathrm{m}^{-2} \mathrm{~d}^{-1}$ [Lohrenz et al., 1992].

In order to add the calculated carbon value $\left(630 \mathrm{mg} \mathrm{C} \mathrm{m}^{-2}\right.$ $\mathrm{d}^{-1}$ ) into the total carbon budget, the following must be known: the residence time of the eddy in the Sargasso Sea and the duration over which the eddy's isopycnals dome above the euphotic depth. These times cannot be determined from the mooring record. Also, the number of eddies that occur in the Sargasso Sea for a given year cannot be ascertained from a single mooring. This emphasizes the importance of combining mooring observations with remote sensing and shipboard ob- servations, as well as modeling, to determine the magnitude of eddy-induced production in closing the carbon budget as estimated by Jenkins [1988].

\section{Conclusion}

A mode water mesoscale eddy passed the Bermuda Testbed Mooring during the month of July 1995 and introduced a substantial amount of nitrate into the euphotic zone. This caused a diatom-dominated phytoplankton response that was apparently the largest observed in 8 years in that area of the Sargasso Sea. Measurements of this transient subsurface event were obtained by emerging chemical and bio-optical sampling systems in combination with traditional shipboard sampling. Peak nitrate levels reached $2.5 \mu \mathrm{mol} \mathrm{L}^{-1}$ at $80 \mathrm{~m}$, with peak chlorophyll $a$ responses of $1.4 \mathrm{mg} \mathrm{m}^{-3}$ at $71 \mathrm{~m}$ and a peak beam attenuation coefficient of nearly $0.7 \mathrm{~m}^{-1}$. Substantial decreases in temperature were observed at all BTM measured depths of the upper layer, thus interrupting the developing seasonal stratification. The mean isotherm doming of the eddy appeared to reach a depth of $\sim 70-80 \mathrm{~m}$. Isopycnal displacements caused by inertial pumping allowed waters in the temperature range of $18^{\circ}-18.5^{\circ} \mathrm{C}$ to reach up to depths of $45 \mathrm{~m}$. The 1\% light level rose from $85-90 \mathrm{~m}$ to a depth of $60-65 \mathrm{~m}$, indicating a substantial increase in particulate matter in the euphotic zone. The nitrate introduced into the euphotic zone during this eddy was estimated from the mooring data to be 7.3 mmol $\mathrm{NO}_{3}^{-} \mathrm{m}^{-2} \mathrm{~d}^{-1}$, yielding a new production of $630 \mathrm{mg} \mathrm{C}$ $\mathrm{m}^{-2} \mathrm{~d}^{-1}$ at the mooring site. Further observations of eddies integrating mooring measurements with shipboard profiling and remote sensing observations, and more extensive modeling are necessary to determine the role of eddies in closing the carbon budget in the Sargasso Sea.

Acknowledgments. We would like to thank Rod Johnson, Norm Nelson, Fred Bahr, and all of the staff at the Bermuda Biological Station for Research who collected and processed the BATS hydrographic and pigment data. Special thanks also to Grace Chang, Derek Manov, Dave Sigurdson, and Sarah Zedler for their work in collecting and processing data from the Bermuda Testbed Mooring and to John Kemp and the captain and crew of the R/V Weatherbird for deploying and recovering the mooring. We are indebted to Dan Frye for his continued collaboration in the design and implementation of the BTM. Support for the BTM project has been provided by the NSF Ocean Technology and Interdisciplinary Coordination Program (TD: OCE9627281). D.J.M. acknowledges the support of JPL contract 960517 and NASA grant NAG5-6455.

\section{References}

Bartz, R., J. R. V. Zaneveld, and H. Pak, A transmissometer for profiling and moored observations in water, Ocean Optics 5, Proc. SPIE Int. Soc. Opt. Eng., 160, 102-107, 1978.

Bartz, R., R. W. Spinrad, and J. C. Kitchen, A low power, high resolution, in situ fluorometer for profiling and moored applications in water, Ocean Optics 9, Proc. SPIE Int. Soc. Opt. Eng., 925, 157-170, 1988.

Bidigare, R. R., J. Marra, T. D. Dickey, R. Iturriaga, K. S. Baker, R. C. Smith, and H. Pak, Evidence for phytoplankton succession and chromatic adaptation in the Sargasso Sea during spring 1985, Mar. Ecol. Prog. Ser., 60, 113-122, 1990.

Booth, C. R., The design and evaluation of a measurement system for photosynthetically active scalar irradiance, Limnol. Oceanogr., 19, 326-335, 1976.

Brzezinski, M. A., and C. A. Kosman, Silica production in the Sargasso Sea during spring 1989, Mar. Ecol. Prog. Ser., 142(1-3), 39-45, 1996.

Dickey, T. D., et al., Initial results from the Bermuda Testbed Mooring program, Deep Sea Res., Part I, 45, 771-794, 1998a. 
Dickey, T. D., D. Frye, J. McNeil, D. Manov, N. Nelson, D. Sigurdson, H. Jannasch, D. Siegel, A. Michaels, and R. Johnson, Upper ocean temperature response to Hurricane Felix as measured by the Bermuda Testbed Mooring, Mon. Weather Rev., 126, 1195-1201, 1998b.

Dugdale, R. C., and J. J. Goering, Uptake of new and regenerated forms of nitrogen in primary productivity, Limnol. Oceanogr., 12, 196-206, 1967.

Falkowski, P. G., D. Ziemann, Z. Kolber, and P. K. Bienfang, Role of eddy pumping in enhancing primary production in the ocean, $\mathrm{Na}$ ture, 352, 55-58, 1991.

Frankignoul, C., Low-frequency temperature fluctuations off Bermuda, J. Geophys. Res., 86, 6522-6528, 1981.

Garside, C., and J. C. Garside, Euphotic-zone nutrient algorithms for the NABE and EqPac study sites, Deep Sea Res., Part II, 42, 335-347, 1995.

Granata, T., J. Wiggert, and T. Dickey, Trapped near-inertial waves and enhanced chlorophyll distributions, J. Geophys. Res., 100, 20,793-20,804, 1995.

Holloway, G., and K. Denman, Influence of internal waves on primary production, J. Plankton Res., 11, 409-413, 1989.

Jannasch, H. W., K. S. Johnson, and C. M. Sakamoto, Submersible, osmotically pumped analyzers for continuous determination of nitrate in situ, Anal. Chem., 66, 3352-3361, 1994.

Jenkins, W. J., Nitrate flux into the euphotic zone near Bermuda, Nature, 331, 521-523, 1988.

Jenkins, W. J., and J. C. Goldman, Seasonal oxygen cycling and primary production in the Sargasso Sea, J. Mar. Res., 43, 465-491, 1985.

Karl, D. M., R. Letelier, D. V. Hebel, D. F. Bird, and C. D. Winn, Trichodesmium blooms and new nitrogen in the North Pacific gyre, in Marine Pelagic Cyanobacteria: Trichodesmium and Other Diazotrophs, edited by E. J. Carpenter et al., pp. 219-237, Kluwer Acad., Norwell, Mass., 1992.

Klein, P., and B. Costa, Effects of wind-stress variability on nutrient transport into the mixed layer, Deep Sea Res., 43, 465-491, 1983.

Knap, A. H., et al., U.S. Joint Global Flux Study, Bermuda Atlantic Time-Series Study, Data Rep. for BATS 1-12, October $1988-$ September 1989, U.S. JGOFS Planning Office, Woods Hole, Mass., 1991.

Knap, A. H., et al., U.S. Joint Global Flux Study, Bermuda Atlantic Time-Series Study, BATS Methods Manual, version 3, Bermuda Biol. Stn. for Res., St. George's, 1993.

Kunze, E., Near-inertial wave propagation in geostrophic shear, $J$. Phys. Oceanogr., 15, 544-565, 1985.

Lai, D. Y., and P. L. Richardson, Distribution and movement of Gulf Stream rings, J. Phys. Oceanogr., 7, 670-683, 1977.

Lewin, J. C., Research on the deposition of silica on the diatom surface, Ref. 60-13, 6 pp., Woods Hole Oceanogr. Inst., Woods Hole, Mass., 1960.

Lewis, M. R., W. G. Harrison, N. S. Oakey, D. Hebert, and T. Platt, Vertical nitrate fluxes in the oligotrophic ocean, Science, 234, 870 873, 1986

Lohrenz, S. E., G. A. Knauer, V. L. Asper, M. Tuel, A. F. Michaels, and A. H. Knap, Seasonal variability in primary production and particle flux in the northwestern Sargasso Sea: U.S. JGOFS Ber- muda Atlantic Time Series Study, Deep Sea Res., Part A, 39, 13731391, 1992.

Marra, J., R. R. Bidigare, and T. D. Dickey, Nutrients and mixing, chlorophyll and phytoplankton growth, Deep Sea Res., Part A, 37, 127-143, 1990.

McGillicuddy, D. J., and A. R. Robinson, Eddy-induced nutrient supply and new production in the Sargasso Sea, Deep Sea Res., Part I, 44, 1427-1450, 1997.

McGillicuddy, D., A. Robinson, D. Siegel, R. Johnson, H. Jannasch, T. Dickey, J. McNeil, A. Michaels, and A. Knap, New evidence for the impact of mesoscale eddies on biogeochemical cycling in the Sargasso Sea, Nature, 394, 263-266, 1998.

Michaels, A. F., and A. H. Knap, Overview of the U.S. JGOFS Bermuda Atlantic Time-Series Study and the Hydrostation S program, Deep Sea Res., Part II, 43, 157-198, 1996.

Nelson, D. M., and M. A. Brzezinski, Diatom growth and productivity in an oligotrophic midocean gyre: A 3-yr record from the Sargasso Sea near Bermuda, Limnol. Oceanogr., 43(3), 473-486, 1997.

Ohlmann, J. C., D. Siegel, and C. Gautier, Ocean mixed layer heating and solar penetration: A global analysis, J. Clim., 9, 2265-2280, 1996.

Parker, C. E., Gulf Stream rings in the Sargasso Sea, Deep Sea Res., 18, 981-993, 1971.

Platt, T., and W. G. Harrison, Biogenic fluxes of carbon and oxygen in the ocean, Nature, 318, 55-58, 1985.

Richman, J. G., C. Wunsch, and N. G. Hogg, Space and time scales of mesoscale motions in the western North Atlantic, Rev. Geophys., 15, 385-420, 1977.

Simpson, J. J., T. D. Dickey, and C. J. Koblinsky, An offshore eddy in the California Current System, I, Interior dynamics, Prog. Oceanogr., 13, 5-49, 1983.

Weller, R. A., The relation of near-inertial motions observed in the mixed layer during the JASIN (1978) experiment to the local wind stress and to the quasi-geostrophic flow field, J. Phys. Oceanogr., 12, 1122-1136, 1982.

Weller, R. A., and E. R. Davis, A vector measuring current meter, Deep Sea Res., Part A, 27, 565-581, 1980.

White, W. B., Doppler shift in the frequency of inertial waves observed in moored spectra, Deep Sea Res., 19, 595-600, 1972.

M. Brzezinski, Marine Biotechnology Laboratory, University of California, Santa Barbara, Santa Barbara, CA 93106. (brzezins @lifesci.lscf.ucsb.edu)

T. Dickey and J. D. McNeil, Ocean Physics Laboratory, University of California, Santa Barbara, 6487 Calle Real, Unit A, Santa Barbara, CA 93117. (tommy@icess.ucsb.edu; jdmac@icess.ucsb.edu)

H. W. Jannasch and C. M. Sakamoto, Monterey Bay Aquarium Research Institute, 7700 Sandholt Road, Moss Landing, CA 95039. (jaha@mbari.org)

D. McGillicuddy, Woods Hole Oceanographic Institution, Woods Hole, MA 02543. (dmcgillicuddy@whoi.edu)

(Received April 23, 1998; revised April 22, 1999; accepted April 29, 1999.) 